\title{
EL SUJETO SIN SUJECIÓN: AUGE Y CAÍDA DE LA SUBJETIVIDAD CONTEMPORÁNEA*
}

\author{
THE SUBJECT WITHOUT SUPPORT: \\ RISE AND FALL OF CONTEMPORARY SUBJECTIVITY
}

Maite Gobantes Bilbao

Universidad de Zaragoza gobantes@unizar.es

Dan Tarodo-Cortes

Universidad de Zaragoza

dantc@unizar.es

$\mathrm{D}$ a la impresión de que en la Historia de Occidente nunca se ha dado más importancia a los sujetos y a su deseo, pero, al mismo tiempo, las voces que hablan de su muerte, su agonía y desvanecimiento, resuenan poderosas: «El hombre es una invención cuya fecha reciente muestra con toda facilidad la arqueología de nuestro pensamiento. Y quizá también su próximo fin» (Foucault, 1968: 375). El teórico francés escribía estas líneas en 1966, sin embargo, la idea estaba ya netamente prefigurada en Nietzsche: tras la muerte de Dios, no hay espacio para el hombre, solo para esa inquietante construcción llamada superhombre: «¡Ante Dios! Mas ahora ese Dios ha muerto. Y ante la plebe nosotros no queremos ser iguales». ¡Vosotros hombres superiores, marchaos del Mercado! (Nietzsche, 2011 [1883]: 451).

Por estas circunstancias, parecía pertinente dedicar un dossier al asunto de la subjetividad en este tiempo que puede ser reconocido, entre otras, con las inscripciones Posmodernidad (Habermas, Baudrillard, Lyotard, Vattimo, Jameson); Modernidad líquida (Bauman); Tardomodernidad, Modernidad Tardía, Segunda Modernidad (Beck); Los citados autores coinciden sin embargo en señalar la crisis como elemento definidor de nuestro tiempo. Así, Habermas postula la posmodernidad como el resultado de una crisis radical de los valores que, proclamados en la Ilustración, constituyeron

\footnotetext{
* El presente trabajo se ha realizado en el marco de las ayudas para la Formación de Profesorado Universitario (FPU) del Ministerio de Educación, Cultura y Deporte (FPU015/04599); y dentro del Grupo de Investigación de referencia HERAF: Hermenéutica y Antropología Fenomenolóica (H05_17R) de la Universidad de Zaragoza, del cual ambos autores son miembros efectivos.
} 
el horizonte de la Modernidad (Habermas, 1985). Por su parte, Lyotard sitúa en la crisis de los grandes metarrelatos legitimadores la esencia de nuestro tiempo: «Simplificando al máximo -afirma- se tiene por 'postmoderna' la incredulidad con respecto a los metarrelatos» (2004: 9). Tiempo, en definitiva, de profunda crisis de los grandes relatos y de valores.

Lo decíamos hace unas líneas: parecía oportuno abrir un espacio para pensar qué sujeta y cómo se sujetan los individuos en este convulso principio de siglo y de milenio. Tan interesante como la cuestión de la subjetividad contemporánea son los fantasmas de su flexibilidad. Un ejemplo: recientemente, un ciudadano holandés, Emile Ratelband, acudió a los tribunales para quitarse veinte años de su carné de identidad ${ }^{1}$.

Este individuo reclamaba que la Justicia se pliegue a su deseo y borre dos décadas de su historia: cabe preguntarse cuál o cuáles quiere borrar: ¿la infancia, la adolescencia, la juventud, la madurez o la senectud, que ya ha comenzado?

Este monográfico de la revista científica Tropelías se propone así abordar el fenómeno de la subjetividad, de su emergencia o -en algunos casos- ausencia, en discursos y textos de diversa naturaleza que fluyen sin cesar hoy. Es comúnmente aceptado que la literatura ha contribuido a configurar la subjetividad del ciudadano desde el S.XVIII y que el cine, en el S.XX, hizo lo propio. En la segunda década del XXI, la nómina de textos que penetran en el sujeto parece haberse multiplicado; solo dos ejemplos: videojuegos y series de televisión, que conviven con los tradicionales: literaturas, cine, filosofía, sociología, etc.

Podemos decirlo de forma radical: salvo en los escritos del tipo manual de instrucciones, el sujeto está siempre -de un modo y otro-en el texto del que es autor y que, siempre, interpela a otros sujetos. La cuestión es que las ciencias humanas y sociales llevan varias décadas intentando ceñirse el traje de otras ciencias, un traje que le incomoda, que no termina de sentarle bien. Así, una parte no insignificante de las ciencias sociales y humanas vive un drama, que no es otro que haber alcanzado un saber que cumple con los requisitos formales del llamado método científico pero que, a duras penas, arroja alguna luz sobre el modo en el que sienten y se sienten los sujetos, esos de los que aspira a saber. La discusión es de vieja data: preocupó -y mucho- a Ortega y Gasset, quien vivió la crisis epistemológica de principios del S. XX y para quien

el investigador de la conciencia se encuentra, a un tiempo, con los hechos y su explicación, con los fenómenos y la ley. Las leyes físicas son dictadas por el físico a los cuerpos: las leyes de la vida espiritual o mental son dictadas por esta misma al filósofo (1983 [1933]: 211)

El filósofo canadiense Charles Taylor ha hecho notar también que afirmaciones consideradas verdaderas a propósito de los objetos de estudio científico, no son válidas a propósito de los sujetos:

Lo que soy como un yo, mi identidad, está esencialmente definido por la manera en la que las cosas son significativas para mí, y el asunto de mi identidad se elabora sólo mediante un lenguaje de interpretación que he aceptado como válida articulación de esas cuestiones. Preguntar lo que es una persona haciendo una abstracción de las interpretaciones que hace de sí misma es plantear una pregunta que, en principio, no tiene

\footnotetext{
${ }^{1}$ Información recogida de una noticia aparecida en la versión española de la web de la BBC (2018, 8 de noviembre): https://www.bbc.com/mundo/noticias-46145019 (fecha de consulta: 31/01/2019).
} 
respuesta. No somos yos de la misma manera que somos organismos, o no poseemos yos de la misma manera que poseemos hígados o corazones. (Taylor, 2006: 61).

Lo que Taylor llama marcos referenciales son los encargados de proporcionar el trasfondo explícito o implícito para nuestros juicios, intuiciones o reacciones morales en cualquiera de las tres dimensiones esenciales, a saber: 1) cuestiones morales, 2) espirituales y 3) referencia a una comunidad definidora. Cuando hablamos de la dignidad de un estatus o de un logro, cuando definimos de una cierta manera nuestras obligaciones morales o juzgamos si una vida es digna de consideración "nos encontramos articulando inter alia lo que aquí vengo llamando «marcos referenciales» (Taylor, 2006: $60)$.

Una vez expuestas estas breves consideraciones teóricas sobre el problema de la subjetividad contemporánea, repasaremos el contenido del presente dossier, que arranca con el análisis de dos de las obras que marcan el inicio de ese tiempo llamado Modernidad. Hablamos de El discurso del método y Las Meditaciones Metafisicas, de Descartes. El investigador Jesús González Requena ha utilizado su propio método - conocido como Teoría del Texto-, ese que lleva más de tres décadas siguiendo y que alienta a deletrear imágenes y escritos para ver lo que habita en ellos. El resultado de tal tarea, en esta ocasión, lleva por título «La pesadilla de Descartes». Y exactamente eso es lo que encuentra González Requena en el corazón de esos dos libros-hito: que en la concepción del sujeto de la Modernidad habita una pesadilla, se halla un pozo (como en el que, en un momento determinado, creyó haber caído Descartes) donde los individuos no pueden sujetarse porque han sido concebidos como meras máquinas de intelección (no muy diferentes, por cierto, a las concebidas desde las perspectivas conductista y cognitivista de nuestra contemporaneidad).

La propuesta de Descartes, como muestra González Requena, está netamente centrada en las matemáticas y geometría como modelos de referencia en los que lograr aislar el significante, y, destaca además, el papel negativo de la duda, una duda que tiene una «intensidad propiamente pulsional: la búsqueda de, al menos una, certeza».

Buena parte de la obra del filósofo Giambattista Vico, objeto de estudio del segundo de los artículos que integran el presente dossier, puede ser entendida como una réplica a la de René Descartes. Alfonso García Marqués firma «La subjetividad contemporánea interpretada diacrónicamente a partir de G.B. Vico», un riguroso estudio -no exento de emoción- que traza la línea de pensamiento viquiano para recorrer de forma diacrónica las diferentes subjetividades y desembocar en la que nos interesa: la subjetividad de nuestros días.

García Marqués subraya la radical novedad que representa, en el S.XVIII, las concepciones viquiana de la mente y de sus modificaciones. El novedoso planteamiento es, en esencia, el siguiente: la subjetividad humana no es ahistórica, sino que ha de ser concebida de modo evolutivo y narrativo. Así, en Vico se halla una diversidad de mentes o posibilidades de pensar y actuar que vienen a romper con la homogeneidad atribuida a la razón humana. Y, además, para completar el cuadro, esa pluralidad de mentes es diacrónica: a través del tiempo se han dado y darán diversos tipos de sujetos y subjetividades, en ocasiones irreductibles entre sí. La procesualidad de lo humano se ve subrayada por 
los conceptos viquianos de corsi y recorsi: la humanidad está en un continuo proceso histórico de nacimiento, crecimiento, decadencia y, de nuevo, comienzo. A diferencia de Vico, para quien las modificaciones eran tres, García Marqués establece que son solamente dos: la mente poética (creadora) y la mente reflexiva, que darían lugar a una subjetividad imaginativa y a una subjetividad racional.

Resulta especialmente interesante la caracterización que el autor realiza de la «razón hipercrítica» en que puede llegar a caer la mente reflexiva. Se trata de un nuevo tipo de subjetividad caracterizada por la filosofía de la sospecha permanente y crítica a todos los valores. La razón crítica elimina toda forma de sociedad a favor de un individualismo que, en su extremo, se asemeja al egoísmo inicial previo a las organizaciones.

García Marqués defiende la fecundidad del modelo viquiano para la compresión tanto de los pueblos remotos de la Antigüedad como de nuestra sociedad hoy: no solo hay pensamiento racional, científico, sino también pensamiento poético, imaginativo, creador que llega a tener una función más importante en la guía y construcción de la sociedad. Ambas formas de pensamiento no se excluyen sino que pueden y deben integrarse en un tipo de sujeto humano que cultive todos esos aspectos en una unidad teleológica superior, que dé lugar a la akmé individual y social, bajo la guía de la razón desplegada.

Las subjetividades de Montaigne y Cervantes han debido de resonar en el investigador Miguel Marinas, quien se ocupa de cómo miran estos dos autores el Nuevo Mundo, ese nuevo Otro que acababa de irrumpir en el escenario europeo. El texto titulado «América, el otro de Montaigne y Cervantes» se ocupa de mirar la mirada - no tanto de lo visto - al tiempo que escenifica una suerte de diálogo entre Montaigne, Cervantes y quien lo firma: Marinas.

La perspectiva teórica en la que se inscribe este artículo es la llamada modernidad del sur. Este modelo, desarrollado por el pensador Carlos Thiebaut, considera que la modernidad no es única ni exclusivamente centroeuropea, racionalista, universalista e ilustrada sino que cabe hablar de otra cosa que puede ser nombrada como modernidad del sur. Se trata de un proceso de construcción de la identidad periférica (respecto a la centroeuropea), de carácter narrativo, más centrada en el sujeto y sus nuevos ethos vitales que en una moral uniforme. De forma implícita, esta perspectiva entraña que sujeto, norma y mundo son mudables y son efecto del deseo, la deliberación y el acuerdo. Por eso, como sostiene el teórico Miguel Marinas, se puede entender que Montaigne y Cervantes son aquí centrales: ellos fundan esa llamada modernidad del sur. La "Mirada" del ensayista francés es la mirada que escucha los relatos que llegan del Nuevo Mundo, que los sopesa y los explora con detalle para, luego, tratar de pensarlos desde la variedad de la condición humana.

Para el colosal escritor español, América es la cifra de su deseo: un deseo que nunca alcanzaría. El artículo concluye con un sugerente esquema del tránsito del nombrar románico al nombrar moderno. Esa nueva cultura, o mejor, nuevo modo de vivir, inspira a Cervantes para componer, por entre algunos de sus relatos, un mapa del mundo nuevo.

Antes de que un 11 de septiembre de 2001 viéramos desplomarse uno de los emblemas del orgullo de la cultura occidental, las Torres Gemelas, lo habíamos visto -con pocas o casi ninguna 
variante- en el cine: Independence Day (1996), Argamenddon (1998), Godzila (1998), Deep Impact (1998) ponían en escena la destrucción de los símbolos de Occidente. El cine de catástrofes -constata González Requena- ha registrado desde los años 70 dos transformaciones relevantes: «un desplazamiento de lo narrativo a lo espectacular» (2008: web), lo que tiene como consecuencia una menor densidad simbólica y, la segunda: el casi abandono de las catástrofes históricas para comenzar a representar catástrofes nuevas, cada vez más devastadoras, que tienen lugar en el presente inmediato (2008: web). Y que ofrecen, por eso mismo, la expresión de una angustia propiamente civilizatoria y llevada a su paroxismo, pues en ellas se vislumbra el horizonte de la destrucción total. El fin -pero esta vez siniestro- de la Historia -es decir, el cese, la desaparición de todo horizonte. Son, por eso, las escenografías apocalípticas de la Posmodernidad.

El fenómeno del cine de catástrofes ha encontrado digno sucesor en lo que se ha dado en llamar distopías postcolapsistas, que han visto en ciertas series de televisión un buen acomodo. El artículo titulado «Preparados para el desastre: survivalismo y colapso en la distopía contemporánea. El caso de The Walking Dead» se ocupa de esta cuestión. Con algunas de las herramientas teóricas que proporcionan los Estudios Culturales, su autora, Ana-Clara Rey Segovia, se adentra en el territorio de la distopía postcolapsista para analizar la serie televisiva The walking dead (Frank Darabont, Angela Kang, AMC, 2010-actualidad). La autora penetra en esas «representaciones encargadas de escenificar futuros indeseables a través de la extrapolación de los males del presente sean estos planteados en términos políticos [...], sociales [...], económicos [...] o ecológicos».

Rey Segovia hace notar que un número considerable de las ficciones distópicas del mainstream contemporáneo suelen desarrollarse en el escenario de una sociedad que ha sufrido el apocalispis, el colapso. La autora establece una interesante relación entre el vigor del imaginario de los grupos survivalistas norteamericanos y las numerosas obras postcolapsistas.

El investigador Víctor Silva Echeto se ocupa en «Subjetividad, comunicación, economía y biopolítica» de realizar un análisis crítico del pensamiento de Agamben. La tesis central del pensamiento del filósofo italiano Giorgio Agamben es que «el ingreso de la zoé en la esfera de la polis, la politización de la nuda vida, constituye el acontecimiento decisivo de la modernidad, que marca una transformación radical de las categorías político-filosóficas del pensamiento clásico». Sin un nexo ético, no solo cognitivo, que vincule palabras, cosas y acciones humanas asistimos a una proliferación sin precedentes de discursos e imágenes vanas. Los medios de comunicación participan sobremanera de ese vaciamiento: juramentos en tertulias sin ningún vínculo que los sostenga, son solo un ejemplo.

Silva Echeto sostiene que, en el caso de Agamben, no se pretende retornar al juramento como mecanismo de lucha contra el vaciamiento del lenguaje, sino que, por el contrario, su propuesta es regresar a la duda filosófica. En ese contexto, muestra Silva Echeto, la filosofía que desde sus inicios asume el riesgo tanto de la verdad como del error, es una crítica al juramento. En una etapa histórica donde las lenguas europeas parecen estar condenadas a jurar en falso y en que la política no puede asumir otra forma que la oikonomia, esto es, palabra vacua sobre la nuda vida, es todavía de la filosofía de donde puede venir, en la sobria conciencia de la situación extrema a la que ha llegado en su historia 
el viviente que tiene el lenguaje, la indicación de una línea de resistencia y de transformación.

Las cuestiones relacionadas con la diferencia sexual, la redefinición de feminidad y masculinidad, la fluidez del género son uno de los temas de nuestro tiempo, casi nos atreveríamos a escribir el artículo antonomásico «El» para referirnos a este asunto: el tema de nuestro tiempo. La investigadora María Angulo Egea ha optado por realizar un análisis del discurso de la cobertura del juicio contra cinco hombres - La Manada- acusados de violar a una joven en los Sanfermines de 2016 como una forma de pensar lo femenino y lo masculino en nuestros días.

La investigadora, experta en estudios de género, ha constatado que los discursos reproducen una ideología que abunda en estereotipos e imaginarios heteropatriarcales. Un relato que ha puesto destaca Angulo- el foco en la víctima, la superviviente, la denunciante, en lugar de centrarse en los hechos y en los agresores; en interpretar acudiendo a fuentes solventes, o en contextualizar y dar cuenta de otros casos de sentencias y juicios por abuso sexual. Un discurso que en bastantes momentos hace esfuerzos por emerger contrastado y respetuoso pero que en demasiadas ocasiones se desliza hacia la estigmatización y revictimización hasta reforzar el estado de desigualdad existente entre la forma de juzgar a las mujeres y a los hombres.

Cambiando el escenario, la propuesta teórica de Verónica Franco nos retrotrae a la adolescencia en ese ejercicio de autoconocimiento y reflexión llamado diario personal o diario íntimo. En su texto «Análisis del discurso autoficcional en los adolescentes: la subjetividad a través del diario», se ofrecen claves para comprender el discurso del diario de los adolescentes mediante el análisis del léxico que utilizan los jóvenes en estos textos tan personales. Tomando como muestra dos clases de secundaria $\left(1^{\circ}\right.$ y $3^{\circ}$ de ESO) puede observarse como el sentimiento subjetivo se gesta desde la infancia y se va moldeando rápidamente durante los primeros años de instituto hacia una subjetividad unida a un fuerte sentimiento de pertenencia a un grupo.

Las connotaciones y el repertorio léxico de los jóvenes participantes de este experimento didáctico forman una radiografía incipiente pero interesante de la subjetividad en esa edad marcada por los cambios físicos y emocionales. La transición hacia la vida adulta queda plasmada en una reiterada repetición de voces relacionadas con el aburrimiento, el estrés y la efusividad, rasgos que parecen ser definitorios de esta sociedad posmoderna incluso a edades tan tempranas.

El diario nos sirve así como puente hacia un bloque de cuatro trabajos cuyo objeto de estudio es el videojuego. Un medio "nuevo", con cada vez más comillas, pues aunque su entrada en la Academia todavía cuente con poco más de dos décadas de historia, estamos próximos al medio siglo de la aparición del que es por muchos considerado el primer videojuego comercial: Pong. El simulador de tenis virtual de Atari se convirtió en 1972 en un éxito sin precedentes que supuso el primer hito en una nueva era global del entretenimiento como industria creativa. El videojuego permitía explotar la subjetividad de una forma nunca antes vista: el sujeto es a la vez observador y participante, forma parte del relato y lo puede manipular y por ello se ha ganado aparecer en el título de este monográfico. Como era de esperar y de una forma paralela a los estudios de cine, décadas después de los juegos pioneros se produjo la entrada del medio en el ámbito académico dentro de los llamados Game Studies. 
En este marco, Alberto Venegas nos propone preguntarnos cómo los videojuegos influyen en la construcción de subjetividades históricas, centrando su artículo en el caso del desembarco de Normandía. Este hecho para la cultura popular representa el triunfalismo de Estados Unidos en la Segunda Guerra Mundial, un lugar hegemónico que se ha logrado al transformar el mero hecho histórico en una suerte de mito cimentado por grandes superproducciones cinematográficas de Hollywood y, más recientemente, por videojuegos que ponen en manos del jugador sentirse un soldado más de las filas del bando ganador.

El trabajo hace hincapié en juegos como Medal of Honor: Allied Assault (EA, 2002) o Call of Duty: WWII (Activision, 2017), que refuerzan una imagen espectacular, ligada a la diversión y vacía de contexto, de un episodio del conflicto bélico que ha servido como baluarte para la formación de esta subjetividad histórica. Venegas llega a esta conclusión acudiendo al concepto de "retrolugar", acuñado por sí mismo, es decir, lugares que plantean reconstruir un pasado idealizado, simplificado que se acerca más por la vía de la inmediatez y la espectacularidad, poniendo dicha subjetividad a la carta del jugador, para que sienta una experiencia en primera persona del conflicto histórico pero desde una perspectiva ligera y poco comprometida, que solo se queda en lo llamativo y superficial.

Luis Navarrete y Juan José Vargas, por su parte, abordan la cuestión de la subjetividad en el videojuego desde una perspectiva estructural. Parten de la teoría de los mundos ficcionales de Lubomir Dolezel para realizar una clasificación de la saturación de los mundos de ficción ludonarrativos, en la que el papel del jugador como sujeto es fundamental.

Esta posición del jugador como testigo en el mundo virtual recreado en el videojuego es clave para determinar si nos encontramos ante mundos de ficción revelados y mundos de ficción no revelados. Mediante del análisis de tres juegos de cada tipo - cada uno representante de una subclase dentro de los mismos- los investigadores son capaces de sentar unas bases estructurales que combinan las teorías ludológicas con la realidad narratológica que es común a todos los relatos. La subjetividad del jugador en esta dualidad lúdico-narrativa es la bisagra que une y hace coherentes todas las interpretaciones de mundos de ficción.

De las características del mundo a explorar en el videojuego pasamos en el siguiente trabajo a centrar el foco en el ente que lo explora: el avatar, o más bien en la subjetividad que hay más allá del mismo. Víctor Navarro Remesal explica en «Ser todo, ser nada: La subjetividad en el videojuego más allá del avatar» que la identificación del jugador puede ir mucho más allá de una encarnación del mismo en el avatar. Existen videojuegos donde se puede "ser muchos" (manejando en grupo o alternativamente diferentes avatares), "ser todo" (cuando el jugador encarna a una especie de dios omnipotente, o directamente se identifica con el mundo jugable) o incluso "ser nada" (fantasmas o vacíos controlables).

A lo largo de este trabajo se presentan 20 tipos de avataridad expandida que no suponen un inventario cerrado, sino más bien una muestra de la riqueza creativa que ofrece el diseño de videojuegos a los creadores a la hora de hacer patentes estas relaciones subjetivas entre el jugador y su representación en el universo jugable. 
El bloque dedicado a los Game Studies se cierra con la propuesta de Santiago Peribáñez, que abandona el videojuego como ente meramente lúdico para adentrarse en el novedoso terreno de los newsgames o videojuegos informativos. En su trabajo, el autor aborda el problema de la subjetividad desde dos puntos de vista: la propia del periodismo y la del videojuego.

Peribáñez analiza uno de los newsgames más complejos desarrollado en España, Montelab, realizado por el Lab RTVE. En él, se retrata en forma de experiencia interactiva la vivencia de una persona que va a comprar o alquilar una casa en la época previa a la gran crisis de 2008, cuando la burbuja del ladrillo crecía rápidamente. Las decisiones del sujeto-jugador le harán vivir diferentes experiencias de las que se pueden extraer unas conclusiones mediante un método empírico de ensayo y error en ese mundo ludoficcional pero basado en hechos muy reales.

Para cerrar este dossier con una reflexión, hemos seleccionado el texto titulado «De cómo en el fragor de la batalla el entrometido dijo "hablemos" y por qué rara razón los contendientes, brazo en alto, detuvieron el gesto y el arma para escucharle/ No es cine para Hombres»; por su título se puede deducir con bastante facilidad: no es un artículo académico. Se trata de un ensayo-relato del teórico Eloy Fernández Porta, del que casi se podría predicar lo que decía Montaigne de sus celebérrimos ensayos: que era él mismo materia de sus escritos. Por otro lado, quizás no sea de extrañar que cuando se reclama un texto sobre subjetividad, pueda responderse con un ejercicio de la misma.

Tras la impresión -falsa, creemos- de fragmentación de este ensayo, se esconde una estructura ajustada a ese asunto llamado subjetividad. Y, en concreto, subjetividad masculina. Fernández Porta entiende que el mundo que habitamos y que da sobradas muestras de estar necesitado de «asesores, prótesis, profes venidos de plácidos campus privados» es un «mundo vaciado de sustancia masculina».

De hecho, este texto es el extraño manifiesto de un sujeto que habita y dialoga sobre qué cosa es y cómo se muestra la masculinidad en la música, en el cine, en el deporte, en el periodismo... La conclusión anidaba ya en el título: «no es país para hombres».

\section{Referencias bibliográficas}

FouCAULT, Michel (1968): Las palabras y las cosas, Editorial S.XXI. México.

TAYLOR, Charles (2006): Fuentes del yo. La construcción de la identidad moderna, Paidós, Barcelona. BAumAn, Zygmunt (2003): Modernidad líquida, FCE, México, 2003.

NIETZSCHE, Friedrich (2011): Así habló Zaratustra, Alianza, Madrid.

Ortega y GAsset, José (1983): Guillermo Dilthey y la idea de vida, Obras Completas, Vol VI, Alianza editorial/ Revista de Occidente, pp 165-217.

LYOTARD, Jean-François (2004): La condición postmoderna, Cátedra, Madrid.

HABERMAS, Jürnger (1985): «La modernidad, un proyecto incompleto», en Hal Foster y otros: $L a$ posmodernidad, Kairos, Barcelona.

GonzÁlez ReQuenA, Jesús (2008): Escenarios de la posmodernidad, Cajaespaña, Valladolid.

Disponible en http:/gonzalezrequena.com/textos-en-linea-0-2/libros-en-linea/el-club-de-lalucha-apoteosis-del-psicopata/home-prueba/ (última consulta: 04/02/2019). 